\title{
Parameters controlling the glycaemic response to breads
}

\author{
Anthony Fardet*, Fanny Leenhardt, Delphine Lioger, Augustin Scalbert and Christian Rémésy \\ Unité des Maladies Métaboliques et Micronutriments, U3M, INRA, Centre de Recherche de Clermont-Ferrand/Theix, \\ 63122 Saint-Genès-Champanelle, France
}

\begin{abstract}
Bread is one of the most widely consumed staple foods worldwide. White-wheat bread, largely consumed in France, is made from highly refined flour, which leads to a low nutrient density. Due to a highly porous structure and gelatinised starch, it is easily broken down during digestion, leading to a rapid increase of glucose released into the bloodstream. Low glycaemic responses are considered favourable to health, especially against a background of diabetes. Literature reports show that selection of raw material is an essential factor in decreasing the glycaemic index (GI) of white bread. There are two means of decreasing the rate of starch degradation: either (i) slowing gastric emptying rate and/or glucose diffusion-absorption through the intestinal mucosa, which can be achieved by incorporating soluble fibre or organic acid in bread, or (ii) limiting starch accessibility to $\alpha$-amylase by using high-amylose cereal varieties and/or incorporating intact cereal grains. Studies on cereal products show that preservation of the food structure during digestion seems to be a more important GI-reducing factor than the degree of starch crystallinity or the presence of soluble fibre. Thus, we should look to produce bread with a more compact food structure or higher density, which is the case in leavened wholewheat bread or bread with intact cereal grains. The baking process should also be improved to achieve this goal, by using, for example, a reduced kneading time or less yeast than usual.
\end{abstract}

Breads: Glycaemic index: Food structure

\section{Introduction}

Bread is consumed in various forms (white-wheat bread, brown bread, whole bread, bran-enriched bread, and multicereal bread, among others). In France, only $15 \%$ of energy intake is derived from bread. An increase in bread consumption in low-bread-consuming countries would be a good way to readjust the carbohydrate:lipid ratio from 45:40 to 55:30 (\% of energy), as is generally recommended. Not only the quantity consumed but also the nutritional quality of bread should be improved. Quality varies widely according to the raw materials and baking processes used.

For example, white-wheat bread is made of refined flour (type 55) impoverished in micronutrients (minerals, vitamins, trace elements, phytomicronutrients, fibre) and therefore having a low nutrient density. Moreover, whitewheat bread elicits a high glycaemic response (increase in plasma glucose concentrations after food intake), thereby increasing the risk of metabolic diseases such as type 2 diabetes, CVD and obesity.

However, the glycaemic response to bread varies widely according to the type of bread studied. The glycaemic index (GI; defined as the area under the blood glucose curve following ingestion of a test food, expressed as a percentage of the corresponding area following an equivalent load of a reference carbohydrate, either glucose or white-wheat bread) given in the Foster-Powell table for ninety-five types of bread (Foster-Powell et al. 2002) varies from 27 (barley bread with $75 \%$ whole grains) to 95 (extremely porous French baguette). This extreme variability reflects very different rates of starch digestion; starch from a French baguette is rapidly digested, leading to a glycaemic response close to that of glucose (GI 100), whereas starch from bread containing intact cereal grains is digested more slowly. Both raw materials and baking processes can therefore influence glycaemic response.

Low to moderate GI $(<70)$ are considered favourable to health, especially for the prevention of CVD, obesity and type 1 or 2 diabetes (Food and Agriculture Organization \& World Health Organization, 1997). Hence, an understanding of the mechanisms underlying such high variability in glycaemic responses for bread appears to be of prime interest. However, in the in vivo studies published, the test foods are rarely well characterised, be it at molecular level (degree of starch gelatinisation and retrogradation, percentage of amylose), at microscopic level (starch interactions with

\footnotetext{
Abbreviation: GI, glycaemic index.

* Corresponding author: Dr Anthony Fardet, fax + 334736246 38, email afardet@clermont.inra.fr
} 
other food components: proteins, lipids, and fibres; food matrix porosity) or the macroscopic level (food particle size, in particular its changes during the digestive process), which obviously sets a limitation to the interpretations of the observed differences in glycaemic response. However, it is true that collecting food samples during digestion is a difficult process, in particular in human subjects.

The objective of the present review is therefore to discuss each of the main parameters controlling the variability of the glycaemic responses observed for bread products. The first part will briefly document the way high-GI bread is digested during gastrointestinal transit; then, we will discuss the parameters affecting GI in bread and explore how they can be modified to improve GI.

\section{Digestion of high-glycaemic-index breads during gastrointestinal transit}

Due to its porous physical structure (generated by the baking process, mechanical kneading and the respiration of the baking yeasts), bread is easily destructured in the mouth and the stomach (Fig. 1). In pigs, $31 \%$ of starch granules are released from the food matrix during chewing. After $4 \mathrm{~h}$ of stomach digestion, the starch granules are no longer embedded in the protein network (Karinthi, 1995). Finally, bread particle size is drastically reduced after bucco-gastric digestion, which favours the subsequent accessibility of starch to pancreatic $\alpha$-amylases in the small intestine (Karinthi, 1995). In contrast, pasta has a lower glycaemic response (and thus a lower GI, about 60), the particles released from the stomach having a more compact physical structure, with starch less accessible to the pancreatic $\alpha$-amylases (Karinthi, 1995). Most of the starch granules in pasta remain embedded in the protein network during bucco-gastric digestion.

The second reason why white-wheat breads have a relatively high GI is the fact that starch is highly gelatinised during the baking process (at a temperature of $250^{\circ} \mathrm{C}$ ), making it particularly accessible to salivary and pancreatic $\alpha$-amylases. This is compounded by the fact that bread has a porous texture, that the protein fraction (gluten) surrounding the starch is degraded, especially in the stomach where it was estimated in pigs that more than half of proteins are degraded, and that all starch granules are released from the food matrix (Karinthi, 1995).

The interactions between starch and proteins play a role in the glycaemic response of white bread since a gluten-free bread shows a significantly higher glycaemic response than normal white bread (Jenkins et al. 1987; Berti et al. 2004). Adding gluten to gluten-free flour does not restore the initial glycaemic response of the bread (Jenkins et al. 1987). This underlines the importance of the natural interactions between starch and proteins as a parameter controlling the glycaemic response of white bread. Microscopic observations effectively show that the gelatinised starch granules of white bread are embedded in a relatively thin protein network (about $1 \mu \mathrm{m})$ (Karinthi, 1995; Juntunen et al. 2002).

\section{White v. wholemeal breads}

It is interesting to note that in most of the studies performed with breads made from a less refined flour (what is called wholemeal flour, which in fact corresponds to white flour with added bran fraction), the glycaemic response is similar to that of white bread, suggesting a similar digestive process despite a higher percentage of fibre (for whole and brown flours). This is a reflection of the fact that, for these breads, it is the food's physical structure (a porous texture with highly gelatinised starch) that governs glycaemic response rather than the nature of the raw materials. Therefore, the baking process and above all the intensity of kneading play an essential role in the physical structure, and then the texture of the food. Furthermore, in the case of wholemeal bread, bran, which is rich in insoluble fibres, constitutes inclusions which could disrupt the gluten network and favour the digestive
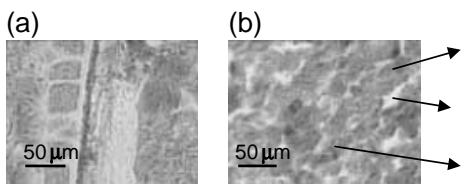

(1) Highly gelatinised starch granules with low amylose content

(2) Highly porous food structure

(3) Low starch-protein interactions

(c) Whole-, brown-, white-wheat

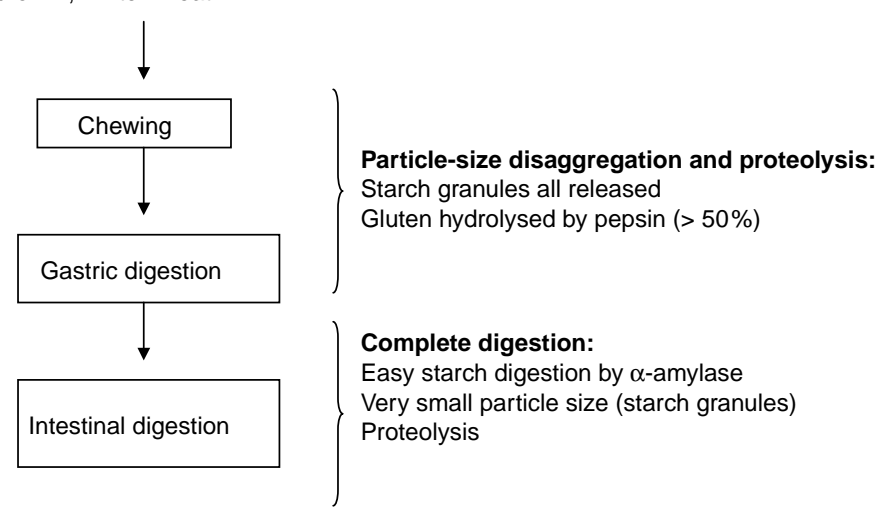

Fig. 1. The different steps in bread digestion. (a) Microscopic structure of whole or brown bread showing bran inclusion, (b) Microscopic structure of white bread, (c) process of bread digestion. 
process. Instead of making whole flour by adding bran to white flour always using the same drastic technological process (for example, intense kneading to compensate for the presence of fibre), it would be preferable to directly use wholegrain flour with the totality of wheat fractions (bran, germ and endosperm). Wholegrain flour contains particles with a more intact structure favourable to a slow starch digestion, and therefore to a lower GI (see values in Table 1 for coarse cereal-kernel breads).

It must be noted that even white bread contains dietary fibre, but in a quantity too small $(2-3 \%)$ to have an effect on the glycaemic response. To our knowledge, no studies have dealt with the impact of fibre from white bread on its glycaemic response. However, the presence of soluble fibres and other microbial exopolysaccharides in white bread (in addition to starch-protein interactions) may partly contribute to its lower GI in comparison with that of pure glucose.

\section{French v. Anglo-Saxon breads}

On the other hand, white or wholemeal bread may have a more moderate glycaemic response depending on the way it is made. For example, most white and wholemeal breads mentioned in the literature are made with white refined flour, with multiple additives, including monoacylglycerols to prevent staling. Monoacylglycerols tend to complex with amylose, leading to a slower rate of starch degradation. In most French white-wheat breads, no monoacylglycerols are added. Moreover there are few determinations of their GI values, and must be considered cautiously as can be seen from values of the Foster-Powell table (Foster-Powell et al. 2002); for example, French baguette was shown to have a GI of 95 , but this value was obtained from only three diabetic subjects (Bornet et al. 1987), and the presence of a gluten network and of soluble fibre (about $2-3 \%$ ) is unlikely to lead to a GI close to that of glucose (GI 100). More recent GI values obtained for French breads (Adam et al. 2003; Rizkalla et al. 2004) are given in Table 1; they range in the GI interval 57-89. Again, the GI value for the traditional French baguette (57 (SEM 9)) must be considered cautiously since it is not significantly different from that of French wholegrain bread (GI 85 (SEM 27)) (Rizkalla et al. 2004).

\section{Different ways to reduce the glycaemic index of breads}

In order to obtain a lower GI for bread, means to reduce starch accessibility need to be identified. This point is particularly relevant for diabetics, who have a limited range of low-GI foods available, especially in terms of cereal products (Björck \& Elmstahl, 2003). Thus, within the hundred cereal products consumed in Western countries, only sixteen have a GI $<70$ and could therefore be considered as low-GI foods. These mainly include pasta products, parboiled rice, intact cereal grains (alone or incorporated in bread), bulgur, couscous and cereal products rich in viscous soluble fibre. Data from the Foster-Powell table (Foster-Powell et al. 2002) indicate that it is possible to reduce the GI of bread (Table 1). There are two ways of reducing starch accessibility to $\alpha$ amylases: modifying the digestive physiology (slowing down of gastrointestinal transit or the speed of glucose diffusion-absorption through the intestinal mucosa); limiting starch accessibility into food particles (Table 2). This can be achieved through the choice of raw materials and technological processes.

\section{Amylose:amylopectin ratio and glycaemic response}

Starch is composed of amylose and amylopectin. Due to its linear (and thus more compact) structure, amylose is hydrolysed more slowly than amylopectin, whose branched structure is more accessible to $\alpha$-amylases.

In wheat flour, amylose is $30 \%$ of the total starch. It has been shown that it is possible to use other cereals that are richer in amylose to complement wheat, such as maize (which can contain up to $70 \%$ amylose), rice (high-amylose varieties) or some barley genotypes (up to $44 \%$ amylose). By mixing wheat flour with other types of flours, it is thus possible to increase the amylose content and significantly reduce the GI of bread (Akerberg et al. 1998). Hoebler et al. (1999) have shown that adding a high-amylose maize to wheat flour led to a significant GI reduction of 40 units in comparison with white-wheat bread. The percentage of resistant starch in the bread enriched with high-amylose maize flour was estimated to be $14 \%$. During digestion, a starch fraction (incompletely gelatinised native amylose) resists enzymic degradation. Muir et al. (1995) have also used scanning electron microscopy to demonstrate the presence of intact starch granules at the end of the small intestine in ileostomised patients who had consumed a meal rich in resistant starch (high-amylose maize bread). Granfeldt et al. (1995a) also achieved a considerable reduction of bread GI $(\mathrm{GI}<50)$ by using bread (arepas) composed of high-amylose maize flour (about $70-75 \%$ starch). In addition to maize, barley or rice, another research direction could therefore be the selection of wheat varieties that are richer in amylose. However, this research has not yet been conducted.

\section{Starch-protein and starch-fibre interactions and glycaemic response}

Another way to reduce GI is to limit starch accessibility to $\alpha$-amylases by total or partial starch encapsulation with other components such as fibres and/or proteins. Hard wheat is characterised by stronger starch-protein interactions than soft wheat. This property is thus used in the manufacturing of pasta where the presence of a structured protein network around the starch granules (associated with a very compact food structure) leads to slow and progressive starch hydrolysis, and therefore to a relatively low GI $(<70)$. We attempted to add wheat semolina in bread to improve GI, but effects were contradictory (Granfeldt et al. 1991; Adam, 2002). In the study of Adam (2002), GI was 74 (Table 1) in comparison with French white bread (used as reference), and in the study of Granfeldt et al. (1991), there was no difference in the GI of white-flour and semolina breads. This may be attributed to the presence of monoacylglycerols usually added into white-flour bread dough leading to a slower rate of starch digestion (complexation of lipids with amylose), which was not the case in the study of Adam (2002). As a result, GI difference between semolina and white-flour breads were attenuated. Other studies are therefore required to confirm the hypoglycaemic potential 
Table 1. Glycaemic indices (GI) of different breads in healthy volunteers* (Mean values with their standard errors)

\begin{tabular}{|c|c|c|c|c|}
\hline \multirow[b]{2}{*}{ Breads } & \multicolumn{2}{|c|}{ GI (glucose = 100) } & \multicolumn{2}{|c|}{ GI $($ bread $=100)$} \\
\hline & Mean & SEM & Mean & SEM \\
\hline \multicolumn{5}{|l|}{ French wheat breads } \\
\hline Pain au lait (Pasquier, France) & 63 & 10 & 90 & \\
\hline Traditional baguette $\dagger$ & 57 & 9 & 82 & \\
\hline Wholegrain bread (loaf) $†$ & 85 & 27 & 122 & \\
\hline Whole bread $\ddagger$ & 55 & & 76 & 12 \\
\hline Semolina bread§ & 52 & & 74 & 13 \\
\hline Leavened whole bread $\ddagger$ & 46 & & 67 & 7 \\
\hline Brown bread§ & 52 & & 74 & 5 \\
\hline Brown bread with bran added§ & 62 & & 89 & 7 \\
\hline Brown bread with boiled bran added§ & 43 & & 61 & 6 \\
\hline \multicolumn{5}{|l|}{ Coarse barley-kernel bread } \\
\hline $80 \%$ intact kernels ( $20 \%$ white-wheat flour) & 40 & & 57 & 10 \\
\hline $80 \%$ scalded intact kernels ( $20 \%$ white-wheat flour) & 34 & & 48 & 10 \\
\hline Barley-kernel bread (50\% kibbled barley) (Australia) & 48 & & 69 & 7 \\
\hline \multicolumn{5}{|l|}{ Barley-flour breads } \\
\hline Wholemeal barley-flour bread & 70 & & 100 & \\
\hline Wholemeal barley-flour ( $80 \%$ ) bread ( $20 \%$ white-wheat flour) & 67 & & 95 & 15 \\
\hline $\begin{array}{l}\text { Wholemeal barley-flour ( } 70 \% \text { ) bread ( } 30 \% \text { white-wheat flour) } \\
\text { baked } 20 \mathrm{~h} \text { at } 120^{\circ} \mathrm{C} \text { (pumpernickel-baking conditions) } \|\end{array}$ & 50 & & 71 & 9 \\
\hline $\begin{array}{l}\text { Wholemeal barley bread, flat, thin, soft (50\% regular barley } \\
\text { flour, } 50 \% \text { high-fibre barley flour) (Sweden) }\end{array}$ & 50 & & 71 & 11 \\
\hline $\begin{array}{l}\text { Wholemeal barley bread, flat, thin, soft ( } 20 \% \text { regular barley } \\
\text { flour, } 80 \% \text { high-fibre barley flour) (Sweden) }\end{array}$ & 43 & & 61 & 7 \\
\hline \multirow{2}{*}{\multicolumn{5}{|c|}{$\begin{array}{l}\text { Wholemeal barley-flour }(80 \%) \text { and white-wheat flour } \\
(20 \%) \text { bread fermented or with added organic acids or salts }\end{array}$}} \\
\hline & & & & \\
\hline Wholemeal barley-flour bread with sourdough (lactic acid) & 53 & & 76 & \\
\hline Wholemeal barley-flour bread with lactic acid & 66 & & 94 & \\
\hline Wholemeal barley-flour bread with calcium lactate & 59 & & 84 & \\
\hline Wholemeal barley-flour bread with sodium propionate & 65 & & 93 & \\
\hline Gluten-free multigrain bread (Country Life Bakeries, Dandenong, Australia) & 79 & 13 & 113 & \\
\hline \multicolumn{5}{|l|}{ Oat breads } \\
\hline $\begin{array}{l}\text { Coarse oat-kernel bread, } 80 \% \text { intact oat kernels } \\
\text { and } 20 \% \text { white-wheat flour }\end{array}$ & 65 & & 93 & 11 \\
\hline Oat-bran bread (50\% oat bran) (Australia) & 44 & & 63 & 10 \\
\hline Oat-bran bread ( $45 \%$ oat bran and $50 \%$ wheat flour) (Sweden) & 50 & & 72 & 10 \\
\hline \multicolumn{5}{|l|}{ Rye breads } \\
\hline $\begin{array}{l}\text { Coarse rye-kernel bread, } 80 \% \text { intact kernels and } \\
20 \% \text { white-wheat flour (Sweden) }\end{array}$ & 41 & & 58 & 8 \\
\hline Sourdough rye & 48 & & 69 & \\
\hline \multicolumn{5}{|l|}{ Wheat bread } \\
\hline $\begin{array}{l}\text { Coarse wheat-kernel bread, } 80 \% \text { intact kernels and } \\
20 \% \text { white-wheat flour (Sweden) }\end{array}$ & 52 & & 74 & 7 \\
\hline \multicolumn{5}{|l|}{ White resistant starch-enriched bread } \\
\hline Fibre white (Nature's Fresh, Auckland, New Zealand) & 77 & 10 & 110 & \\
\hline Wholemeal (wholewheat) wheat-flour bread (Canada) & 72 & 6 & 103 & \\
\hline Wholemeal (wholewheat) wheat-flour bread (South Africa) & 75 & 9 & 107 & \\
\hline $\begin{array}{l}\text { Wholemeal (wholewheat) wheat-flour bread } \\
\text { (Tip Top Bakeries, Australia) }\end{array}$ & 77 & 9 & 110 & \\
\hline \multicolumn{5}{|l|}{ Specialty wheat breads } \\
\hline 9-Grain Multi-Grain (Tip Top Bakeries, Australia) & 43 & 5 & 61 & \\
\hline Multigrain loaf, spelt wheat flour (Australia) & 54 & 10 & 77 & \\
\hline Multigrain (50\% kibbled wheat grain) & 43 & & 61 & \\
\hline Sourdough wheat (Australia) & 54 & & 77 & \\
\hline White-wheat-flour flatbread (Sweden) & 79 & & 113 & 13 \\
\hline \multicolumn{5}{|l|}{ Unleavened bread } \\
\hline Lebanese bread, white (Seda Bakery, Sydney, Australia) & 75 & 9 & 107 & \\
\hline Middle Eastern flatbread & 97 & 29 & 139 & \\
\hline \multicolumn{5}{|l|}{ Spelt wheat bread } \\
\hline Spelt multigrain bread (Pav's bakery, Australia) & 54 & 10 & 77 & 14 \\
\hline White-wheat-flour bread (Canada) & 69 & 5 & 99 & \\
\hline White-wheat-flour bread (Sunblest; Tip Top Bakeries, Australia) & 70 & & 100 & \\
\hline
\end{tabular}

* Values are from the Foster-Powell table (Foster-Powell et al. 2002) unless otherwise indicated, and were obtained with at least eight healthy volunteers. When bread was the reference food used in the original study, the GI value for the food was multiplied by 0.7 to obtain the GI with glucose as the reference food (and by 1.43 when glucose was the initial reference food). When the food reference is bread, GI values should be considered cautiously since white wheat bread has various origins and may therefore have different Gl; besides, values above 100 in the right-hand column have no real physiological relevance compared with the Gl of 100 for reference white wheat bread.

† From Rizkalla et al. (2004).

‡ From Adam et al. (2003)

$\S$ From Adam (2002).

|| From Akerberg et al. (1998). 
Table 2. Different means to reduce the glycaemic index of bread

\begin{tabular}{|c|c|}
\hline Modifications realised & Effect obtained \\
\hline $\begin{array}{l}\text { On the raw materials } \\
\text { Amylose:amylopectin ratio } \\
\text { Starch encapsulation by protein or fibre } \\
\text { Incorporation of intact cereal kernels }\end{array}$ & Limitation of the starch accessibility to $\alpha$-amylase within the food matrix \\
\hline $\begin{array}{l}\text { On the raw materials } \\
\text { Adding soluble fibre ( } \beta \text {-glucans, arabinoxylans) } \\
\text { Adding organic acids }\end{array}$ & $\begin{array}{l}\text { Modification of digestive physiology } \\
\text { Increased viscosity of the digestive medium } \\
\text { Slowing of gastric emptying rate }\end{array}$ \\
\hline $\begin{array}{l}\text { On the technological process } \\
\text { Use of leaven (organic acids) instead of regular yeast } \\
\text { Short kneading and/or long fermentation time }\end{array}$ & More compact structure and slowing of gastric emptying rate \\
\hline
\end{tabular}

of semolina. If the GI reduction of bread semolina was confirmed, such a raw material could be incorporated into the baking mix, especially since semolina is richer in proteins and minerals than soft wheat flour. On the other hand, in most of the studies performed, the use of whole flour (wheat-, barley- or rye-based) richer in fibre did not modify the GI of the breads (Jenkins et al. 1981, 1983, 1986; Liljeberg et al. 1992; Leinonen et al. 1999). As discussed previously, in these studies, the process remained drastic enough to alter the physical structure of the raw materials. However, in the studies of Adam (2002) and Adam et al. (2003), brown and whole breads exhibit a lower GI (74 and 76 , respectively) than white-wheat bread. Again, these contradictory results could be attributed to the presence of monoacylglycerols in the white bread recipes used in most studies, unlike the French white bread recipe used in the study of Adam et al. (2003) which led to a higher GI.

\section{Use of intact cereal grains in bread and glycaemic response}

To preserve the physical structure of the food matrix, breads may be made by incorporating into the flour intact cereal grains in which a fibrous network (insoluble fibre) surrounds the starch, limiting the degree of starch gelatinisation and forming a physical barrier to $\alpha$-amylases. The GI of a bread baked from $40 \%$ intact parboiled barley grains and $60 \%$ white flour is 68 . The GI was 33 when the percentage of barley grains was $80 \%$ (Liljeberg \& Bjorck, 1994). The same authors (Liljeberg et al. 1992), as well as Jenkins et al. (1986) and Holm \& Björck (1992), obtained similar results with rye (GI 46) and wheat grains (GI 68), respectively, but no effect was observed with oat grains (see also Table 1). In this last case, the absence of effect on GI was attributed to the fact that oat grains are more easily destructured during the thermal process than grains of other cereals. Another positive benefit of using intact cereal grains is the preservation of food particles in the gastrointestinal tract, especially at the gastric level; solid foods are indeed emptied more slowly than liquid foods from the stomach. The glycaemic response is thus slowed down. The use of whole grains in bread may therefore result in low GI values associated with the unmilled and unrefined cereals.

\section{Use of viscous soluble fibre in breads and glycaemic response}

Other authors have also shown a positive effect on GI reduction of adding viscous fibre (soluble fibre) (Jenkins et al. 1978; Würsch \& Pi-Sunyer, 1997). The objective was not to form a physical barrier between starch and $\alpha$-amylases, but to increase the viscosity of the digestive medium, especially the thickness of the unstirred layer at the level of the intestinal mucosa, limiting the diffusion and thus the absorption of glucose through epithelial cells (Lund et al. 1989; Würsch \& Pi-Sunyer, 1997). The mobility of the digestive fluids at the level of intestinal microvilli is thus greatly reduced. There may also be interactions between soluble fibre and the mucopolysaccharides of the digestive mucosa (Johnson \& Gee, 1981; Flourie et al. 1984). Several types of fibre have been successfully tested: oat fibre (Holm \& Björck, 1992), barley fibre rich in $\beta$-glucans (Liljeberg et al. 1996), arabinoxylans (Lu et al. 2000, 2004) or the use of cereal varieties naturally rich in soluble fibre (Holm \& Björck, 1992).

Thus, Liljeberg et al. (1996) have shown with whole barley-based breads rich in soluble fibre ( $\beta$-glucans) (50 and $80 \%$ substitution of the barley flour) that it was possible to lower the GI (in comparison with a reference bread) by 30 and 40 units, respectively. The hypoglycaemic effect was all the more important because the $\beta$-glucan content of the barley flour was high (Cavallero et al. 2002). However, in order to have a positive effect, soluble fibres must be incorporated into the food or consumed at the same time as the tested food. Moreover, the fibre must not be destructured, since there is a risk that their rheological properties (especially viscosity) will be modified in the intestine, thus decreasing the GI reduction (Wood et al. 1994). For instance, due to their linear structure, barley and oat $\beta$-glucans are very sensitive to depolymerisation during the technological process (baking or isolation of $\beta$-glucan-rich fraction by water), which in turn reduces their viscosity in vivo. The viscosity of $\beta$-glucans therefore depends not only on their molecular weight but also on quantity added. Würsch \& PiSunyer (1997) thus conclude in their review that a $50 \%$ reduction of the glycaemic peak can be achieved with a $10 \%$ $\beta$-glucans concentration in the cereal product. We thus succeeded in reducing the glycaemic response of bread by $46 \%$ in diabetic patients (type 2) by incorporating oat bran concentrates ( $9 \mathrm{~g} \beta$-glucans/d) to white-wheat bread (Pick et al. 1996).

In addition to $\beta$-glucans found in barley and oat fibre, arabinoxylan (about $88 \%$ of NSP in endosperm and 64-9\% in the bran fraction), a by-product of wheat flour processing (but also found in rye in significant proportion), was also shown to reduce glycaemic response when incorporated in bread at a level of 7 and 14\% (Lu et al. 2000, 2004). 
Arabinoxylans is a hemicellulose composed of a backbone of xylose with arabinose side chains. The mechanism by which it reduces GI is supposed to be the same as that of $\beta$ glucans: delayed gastric emptying and lowering of the rate of diffusion of nutrients from the intestinal lumen to the absorptive membrane (Lund et al. 1989). The arabinoxylans must be incorporated at high levels in bread recipes (7$14 \%$ ) to have a physiological effect, well above the $5 \%$ naturally found in wholewheat flour.

It seems that the hypoglycaemic effect is stronger when soluble fibre forms an intrinsic part of the food matrix than when it is added to the food (Brennan et al. 1996). From this point of view, the preservation of intact cellular structure would favour interactions with other components of the food matrix, and thus influence their subsequent digestion. The use of oat bran or barley varieties naturally rich in $\beta$-glucans (for instance, the variety prowashonupana: $18 \%$ $\beta$-glucans) may therefore be preferable to the addition of various cereal fibres or other sources of soluble fibre (gums or mucilages such as guar gum or psyllium fibre; Würsch \& Pi-Sunyer, 1997a). Another advantage of using viscous soluble fibres is their positive effect on the reduction of LDL-cholesterol (Glore et al. 1994).

\section{Organic acids in breads and glycaemic response}

It is well known that some organic acids, such as acetic, propionic and lactic acids, have the ability to slow gastric emptying when they are included as bread ingredients or naturally produced by leaven fermentation. A reduction in the gastric emptying rate has thus been shown with breads enriched with sodium propionate (Darwiche et al. 2001), lactic acid (Liljeberg \& Bjorck, 1996), acid salts (calcium lactate and sodium propionate) (Liljeberg et al. 1995) or consumed with vinegar (Liljeberg \& Bjorck, 1998) (Table 1). In addition to a decrease in gastric emptying rate, organic acids could also contribute to reinforcing the interactions between starch and protein (gluten), thus limiting enzymic accessibility (Ostman et al. 2002b). The effect is positive if the acid is present during the gelatinisation of starch, but not after the thermal treatment (Ostman et al. 2002b). Sourdough bread, using a leaven prepared from the previous day's dough, has a globally slightly lower GI than regular bread baked with yeast (Adam et al. 2003), but it is difficult to know whether we can attribute these differences to the increase in their density or to the specific effects of the organic acids they contain. Due to other beneficial effects of leaven (for example, the partial hydrolysis of phytic acid leading to enhanced mineral bioavailability), it should therefore be preferable to use leaven instead of yeast in order to produce natural organic acids rather than simply adding organic salts.

\section{Baking conditions and glycaemic response}

Different baking conditions have been tested to reduce the GI of bread. Thus a GI reduction of $30 \%$ has been obtained with a high-amylose barley bread baked $20 \mathrm{~h}$ at $120^{\circ} \mathrm{C}$ (i.e. pumpernickel-baking conditions) instead of the conventional $45 \mathrm{~min}$ at $200^{\circ} \mathrm{C}$ (Akerberg et al. 1998). Such conditions favour the formation of crystalline amylose (annealing) and increase the resistant starch content of about $10 \%$.

\section{Conclusion and perspectives}

The parameters governing the glycaemic response of bread are complex. Four factors are particularly important in slowing gastric emptying and digestion rate: the preservation of the food structure's cohesiveness during the digestive process; the degree of starch crystallinity; the viscosity of the digestive medium; the presence of organic acid. The physical structure of bread is the most important; the more compact the structure (particle state is maintained longer during the digestive process and area accessible to $\alpha$ amylase is thus reduced), the lower the glycaemic response. Physical structure is more preponderant than degree of starch gelatinisation or presence of viscous fibre in determining glycaemic response (Granfeldt et al. 1995b). Studies carried out with other cereal foods, i.e. intact cereal grains or pasta, led to the same conclusions (Granfeldt et al. 1991). Breads with a high-food-structure cohesiveness are mainly breads with intact cereal grains or sourdough breads.

The development and consumption of bread products of high density should thus be encouraged. This could be achieved by reducing the kneading time and increasing the duration of fermentation (about $15 \mathrm{~h}$ ), together with a reduction in yeast quantity. This kind of bread would exhibit a more compact crumb and a less porous food structure, leading to a moderate GI; moreover, this baking process would also prevent the oxidation of vitamin $E$ and carotenoids.

A reduction in GI of starchy foods is often accompanied by a significant increase in resistant starch content (Björck et al. 2000) (resistant starch mainly includes retrograded starch upon cooling and physically inaccessible starch). This has positive consequences on colonic physiology since resistant starch behaves like fibre and is fermented by the colonic microflora into short-chain volatile fatty acids, in particular butyric acid, a preferred substrate for colonic mucosal cells. This acid may play a protective role against colon cancer. Consumption of low-GI foods also induces a prolonged satiety effect after the meal (Ostman et al. $2002 a, b)$. This physiological effect is very interesting because it may limit snacking, which is often considered a risk factor for metabolic diseases such as obesity.

The data reviewed in the present paper allow us to envisage an ideal bread composed of a mix of cereals: wholewheat or brown flour (with a high nutritional density, rich in protective micronutrients) enriched with flour containing a proportion of soluble fibre (derived from rye, oats or barley) compatible with the baking process, and containing a small quantity of intact cereal grains. Last, it would be preferable to apply a baking procedure with leaven instead of yeast alone, in order to obtain a bread rich in organic acids and not too porous. The combination of steam rye grains, oat bran concentrate with $17 \% \beta$-glucans, and of sourdough has thus been successfully attempted, leading to a significant reduction in the glycaemic response (GI about 50) in comparison with usual white bread (white-wheat flour; GI 100) (Ostman et al. 2006). However, one may question whether such a bread would fulfil consumer 
demand. In traditionally white-bread-consuming countries (as in France), we should try to enhance the density of the bread and use type 80 flour (that is $0.8 \mathrm{~g}$ ashes $/ 100 \mathrm{~g}$ flour); and for this, it is interesting to mix white-wheat flour with about $25-40 \%$ coarsely ground wheat grains after a prefermentation to hydrate fibre, destroy phytic acid and improve the baking process. In Scandinavian countries and Germany, it is undoubtedly easier to use whole flour or to add intact cereal grains since these countries are already used to eating these kinds of bread. In the end, it seems that many consumers are now ready to make the switch from white bread to a brown bread with a better physical structure and nutritional quality.

The overly high GI of bread has often been underlined; however, nutritional quality cannot be reduced to this sole parameter. For example, many countries incorporate fats in bread mixes. This reduces GI, but also increases fat intake. In fact, provided whole or brown flour is used, bread has a higher nutritional quality due to the presence of minerals and micronutrients, and its consumption can certainly be recommended, in particular in complex and well-balanced meals. This can be made possible by promoting a change in eating habits and by informing the consumer of the nutritional advantages of such breads.

\section{References}

Adam A (2002) Qualité nutritionnelle et effets métaboliques des farines de blé et du pain (Nutritional quality and metabolic effects of wheat flours and bread). $\mathrm{PhD}$ Thesis, Université d'Auvergne et Université Blaise Pascal.

Adam A, Leenhardt F, Lopez HW, Leuillet M \& Rémésy C (2003) Les possibilités d'amélioration de la valeur nutritionnelle du pain (Possibilities for improvement of the nutritional value of bread). Cahiers de Nutrition et Diététique 38, 316-322.

Akerberg A, Liljeberg H \& Bjorck I (1998) Effects of amylose/amylopectin ratio and baking conditions on resistant starch formation and glycaemic indices. Journal of Cereal Science 28, 71-80.

Berti C, Riso P, Monti LD \& Porrini M (2004) In vitro starch digestibility and in vivo glucose response of gluten-free foods and their gluten counterparts. European Journal of Nutrition $\mathbf{4 3}$, 198-204.

Björck I \& Elmstahl HL (2003) The glycaemic index: importance of dietary fibre and other food properties. Proceedings of the Nutrition Society 62, 201-206.

Björck I, Liljeberg H \& Ostman E (2000) Low glycaemic-index foods. British Journal of Nutrition 83, Suppl. 1, S149-S155.

Bornet FR, Costagliola D, Rizkalla SW, Blayo A, Fontvieille AM, Haardt MJ, Letanoux M, Tchobroutsky G \& Slama G (1987) Insulinemic and glycemic indexes of six starch-rich foods taken alone and in a mixed meal by type 2 diabetics. American Journal of Clinical Nutrition 45, 588-595.

Brennan CS, Blake DE, Ellis PR \& Schofield JD (1996) Effects of guar galactomannan on wheat bread microstructure and on the in vitro and in vivo digestibility of starch in bread. Journal of Cereal Science 24, 151-160.

Cavallero A, Empilli S, Brighenti F \& Stanca A (2002) High $(1 \rightarrow 3,1 \rightarrow 4)$ - $\beta$-glucan barley fractions in bread making and their effects on human glycemic response. Journal of Cereal Science 36, 59-66.

Darwiche G, Ostman EM, Liljeberg HG, Kallinen N, Bjorgell O, Björck IM \& Almer LO (2001) Measurements of the gastric emptying rate by use of ultrasonography: studies in humans using bread with added sodium propionate. American Journal of Clinical Nutrition 74, 254-258.

Flourie B, Vidon N, Florent CH \& Bernier JJ (1984) Effect of pectin on jejunal glucose absorption and unstirred layer thickness in normal man. Gut 25, 936-941.

Food and Agriculture Organization \& World Health Organization (1997) Carbohydrates in Human Nutrition, Report of a joint FAO/WHO Expert Consultation, Rome, 14-18 April 1997. Rome: FAO/WHO.

Foster-Powell K, Holt SH \& Brand-Miller JC (2002) International table of glycemic index and glycemic load values: 2002. American Journal of Clinical Nutrition 76, 5-56.

Glore SR, Van Treeck D, Knehans AW \& Guild M (1994) Soluble fiber and serum lipids: a literature review. Journal of the American Dietetic Association 94, 425-436.

Granfeldt Y, Björck I \& Hagander B (1991) On the importance of processing conditions, product thickness and egg addition for the glycaemic and hormonal responses to pasta: a comparison with bread made from 'pasta ingredients'. European Journal of Clinical Nutrition 45, 489-499.

Granfeldt Y, Drews A \& Björck I (1995a) Arepas made from high amylose corn flour produce favorably low glucose and insulin responses in healthy humans. Journal of Nutrition 125, $459-465$.

Granfeldt Y, Hagander B \& Björck I (1995b) Metabolic responses to starch in oat and wheat products. On the importance of food structure, incomplete gelatinization or presence of viscous dietary fibre. European Journal of Clinical Nutrition 49, $189-199$.

Hoebler C, Karinthi A, Chiron H, Champ M \& Barry JL (1999) Bioavailability of starch in bread rich in amylose: metabolic responses in healthy subjects and starch structure. European Journal of Clinical Nutrition 53, 360-366.

Holm J \& Björck I (1992) Bioavailability of starch in various wheat-based bread products: evaluation of metabolic responses in healthy subjects and rate and extent of in vitro starch digestion. American Journal of Clinical Nutrition 55, 420-429.

Jenkins DJ, Ghafari H, Wolever TM, Taylor RH, Jenkins AL, Barker HM, Fielden H \& Bowling AC (1981) Glycemic index of foods: a physiological basis for carbohydrate exchange. Diabetologia 34, 362-366.

Jenkins DJ, Wolever TM \& Jenkins AL (1987) Glycemic index of processed wheat products. Diabetes Care 46, 631-635.

Jenkins DJ, Wolever TM, Jenkins AL, Giordano C, Giudici S, Thompson LU, Kalmusky J, Josse RG \& Wong GS (1986) Low glycemic response to traditionally processed wheat and rye products: bulgur and pumpernickel bread. American Journal of Clinical Nutrition 43, 516-520.

Jenkins DJ, Wolever TM, Jenkins AL, Lee R, Wong GS \& Josse R (1983) Glycemic response to wheat products: reduced response to pasta but no effect of fiber. Diabetes Care 6, 155-159.

Jenkins DJ, Wolever TM, Nineham R, Taylor R, Metz GL, Bacon S \& Hockaday TD (1978) Guar crispbread in the diabetic diet. British Medical Journal 2, 1744-1746.

Johnson IT \& Gee JM (1981) Effect of gel-forming gums on the intestinal unstirred layer and sugar transport in vitro. Gut 22, $398-403$.

Juntunen KS, Niskanen LK, Liukkonen KH, Poutanen KS, Holst JJ \& Mykkanen HM (2002) Postprandial glucose, insulin, and incretin responses to grain products in healthy subjects. American Journal of Clinical Nutrition 75, 254-262.

Karinthi (1995) Degradations physiques et chimiques subies par des aliments céréaliers are cours des digestions buccales et gastriques (Chemical and physical degradations undergone by cereal products during buccogastric digestion). PhD Thesis, Institut National Agronomique Paris-Grignon (INAP-G) \& 
institut de la Recherche Agronomique (INRA) de Nantes, France.

Leinonen K, Liukkonen K, Poutanen K, Uusitupa M \& Mykkanen H (1999) Rye bread decreases postprandial insulin response but does not alter glucose response in healthy Finnish subjects. European Journal of Clinical Nutrition 53, 262-267.

Liljeberg H \& Björck I (1994) Bioavailability of starch in bread products. Postprandial glucose and insulin responses in healthy subjects and in vitro resistant starch content. European Journal of Clinical Nutrition 48, 151-163.

Liljeberg H \& Björck I (1998) Delayed gastric emptying rate may explain improved glycaemia in healthy subjects to a starchy meal with added vinegar. European Journal of Clinical Nutrition 52, 368-371.

Liljeberg H, Granfeldt Y \& Björck I (1992) Metabolic responses to starch in bread containing intact kernels versus milled flour. European Journal of Clinical Nutrition 46, 561-575.

Liljeberg HG \& Björck IM (1996) Delayed gastric emptying rate as a potential mechanism for lowered glycemia after eating sourdough bread: studies in humans and rats using test products with added organic acids or an organic salt. American Journal of Clinical Nutrition 64, 886-893.

Liljeberg HG, Granfeldt YE \& Björck IM (1996) Products based on a high fiber barley genotype, but not on common barley or oats, lower postprandial glucose and insulin responses in healthy humans. Journal of Nutrition 126, 458-466.

Liljeberg HG, Lonner CH \& Björck IM (1995) Sourdough fermentation or addition of organic acids or corresponding salts to bread improves nutritional properties of starch in healthy humans. Journal of Nutrition 125, 1503-1511.

Lu ZX, Walker KZ, Muir JG, Mascara T \& O'Dea K (2000) Arabinoxylan fiber, a byproduct of wheat flour processing, reduces the postprandial glucose response in normoglycemic subjects. American Journal of Clinical Nutrition 71, $1123-1128$.

Lu ZX, Walker KZ, Muir JG \& O'Dea K (2004) Arabinoxylan fibre improves metabolic control in people with type II diabetes. European Journal of Clinical Nutrition 58, 621-628.
Lund EK, Gee JM, Brown JC, Wood PJ \& Johnson IT (1989) Effect of oat gum on the physical properties of the gastrointestinal contents and on the uptake of D-galactose and cholesterol by rat small intestine in vitro. British Journal of Nutrition 62, 91-101.

Muir JG, Birkett A, Brown I, Jones G \& O'Dea K (1995) Food processing and maize variety affects amounts of starch escaping digestion in the small intestine. American Journal of Clinical Nutrition 61, 82-89.

Ostman EM, Frid AH, Groop LC \& Björck IM (2006) A dietary exchange of common bread for tailored bread of low glycaemic index and rich in dietary fibre improved insulin economy in young women with impaired glucose tolerance. European Journal of Clinical Nutrition 60, 334-341.

Ostman EM, Liljeberg Elmstahl HG \& Björck IM (2002a) Barley bread containing lactic acid improves glucose tolerance at a subsequent meal in healthy men and women. Journal of Nutrition 132, 1173-1175.

Ostman EM, Nilsson M, Liljeberg Elmstahl HGM, Molin G \& Björck IME (2002b) On the effect of lactic acid on blood glucose and insulin responses to cereal products: mechanistic studies in healthy subjects and in vitro. Journal of Cereal Science 36, 339-346.

Pick ME, Hawrysh ZJ, Gee MI, Toth E, Garg ML \& Hardin RT (1996) Oat bran concentrate bread products improve long-term control of diabetes: a pilot study. Journal of the American Dietetic Association 96, 1254-1261.

Rizkalla SW, Laromiguiere M, Bruzzo F, Boillot J \& Slama G (2004) Détermination de l'index glycémique et insulinémique de pains français chez l'homme sain et diabétique (Determination of glycemic and insulinemic indexes of French bread in healthy and diabetic men). Industrie des Céréales 139, 11-14.

Wood PJ, Braate JT, Scott FW, Riedel KD, Wolynetz MS \& Collin MW (1994) Effect of dose and modification of viscous properties of oat gum on plasma glucose and insulin following an oral glucose load. British Journal of Nutrition 72, 731-743.

Würsch P \& Pi-Sunyer FX (1997) The role of viscous soluble fiber in the metabolic control of diabetes. A review with special emphasis on cereals rich in beta-glucan. Diabetes Care $\mathbf{2 0}$, 1774-1780. 